\title{
SGLT 2 Inhibitors; glycemic control, weight loss and safety profile in patients with type 2 Diabetes, at Medicell Institute (MIDEM)
}

\author{
Erum Sohail', Tasnim Ahsan', \\ Saima Ghaus ${ }^{3}$, Wasfa Aijaz
}

\begin{abstract}
Background \& Objective: Sodium glucose co-transporter-2 inhibitors (SGLT 2 inhibitors) are newer antihyperglycemic agents, which improve glycemic control independent of insulin secretion with a low risk of hypoglycemia. This study aimed to assess the efficacy of SGLT 2 inhibitors in terms of glycemic control, weight reduction and safety profile in our patients with type 2 Diabetes (T2D).

Methods: This is a prospective analysis, conducted at Medicell Institute of Diabetes, Endocrinology and Metabolism (MIDEM), Karachi Pakistan from January 2018 till July 2019. This study included patients with T2D, who were treated with SGLT 2 inhibitors add on to other anti-diabetic drugs. Baseline and follow up weight, BMI, HbA1c, blood pressure (BP), renal function and side effect profile was assessed.

Results: Study included 140 patients; $53 \%$ females and $47 \%$ males. Mean Age was $55.6 \pm 10.3$ years. Mean weight at baseline was $81.5 \pm 16.5 \mathrm{~kg}$. Mean duration of T2D was $10.3 \pm 6.75$ years, with a mean $\mathrm{HbA1C}$ at baseline of $9.1 \pm 1.6 \%$. Follow up data was available for 90 patients at the time of analysis. HbA1C improved considerably to $7.6 \pm 0.9(P \leq 0.001)$ and mean weight reduced to $78.5 \pm 16.1 \mathrm{~kg}(P \leq 0.003)$, at first follow-up. Conclusion: Dapagliflozin and Empagliflozin offer a significant additional drug in improving glycemic control with the additional advantage of weight loss and hypoglycemia safety.
\end{abstract}

KEYWORDS: SGLT 2 Inhibitors, Efficacy, Safety, Glycemic control.

doi: https://doi.org/10.12669/pjms.37.1.2701

How to cite this:

Sohail E, Ahsan T, Ghaus S, Aijaz W. SGLT 2 Inhibitors; glycemic control, weight loss and safety profile in patients with type 2 Diabetes, at Medicell Institute (MIDEM). Pak J Med Sci. 2021;37(1):87-92. doi: https://doi.org/10.12669/pjms.37.1.2701

This is an Open Access article distributed under the terms of the Creative Commons Attribution License (http://creativecommons.org/licenses/by/3.0), which permits unrestricted use, distribution, and reproduction in any medium, provided the original work is properly cited.

1. Dr. Erum Sohail, FCPS, MBBS.

2. Prof. Tasnim Ahsan, MRCP(UK), FRCP(Glasg), FRCP(Edin), FRCP(Lon).

3. Dr. Saima Ghaus, FCPS, MBBS.

4. Dr. Wasfa Aijaz, FCPS, MBBS.

1-4: Medicell Institute of Diabetes Endocrinology \& Metabolism (MIDEM),

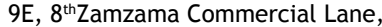
Phase-V, DHA, Karachi, Pakistan.

Correspondence:

Dr. Erum Sohail,

Medicell Institute of Diabetes Endocrinology

\& Metabolism (MIDEM)

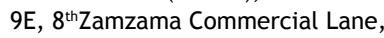

Phase-V, DHA, Karachi, Pakistan.

Email: erum_nathani@yahoo.com

* Received for Publication:

* $1^{\text {st }}$ Revision Received:

* $2^{\text {nd }}$ Revision Received:

* Final Revision Accepted:
April 16, 2020

July 10,2020

October 5, 2020

October 12, 2020

\section{INTRODUCTION}

T2D is a major global public health concern. Just fewer than half a billion people are living with diabetes worldwide and the number is projected to increase by $25 \%$ in 2030 and $51 \%$ in 2045. ${ }^{1}$ Apart from inter-ethnic differences in genetic predisposition, Asian patients with T2D have several distinctive features; high prevalence of young-onset diabetes, ${ }^{2}$ metabolic syndrome, $\beta$-cell dysfunction, ${ }^{3}$ and a higher degree of insulin resistance (particularly in South Asians). ${ }^{4,5}$ They also have lower lean muscle mass, higher visceral fat mass, lower circulating adiponectin levels, ${ }^{6}$ and are more likely to exhibit postprandial hyperglycaemia. ${ }^{7}$ According to IDF 2019 estimates, prevalence of diabetes in Pakistan 
is reported as 19.4 million, ${ }^{1}$ whereas two recent national surveys reported prevalence of diabetes as $26.4 \%$ and $16.9 \%$, and pre-diabetes prevalence of $14.4 \%$ and $10.9 \%$, respectively. ${ }^{8,9}$ There is a continuing unmet need for novel glucose lowering therapies that provide durable glycemic control while avoiding hypoglycemia, weight gain, fluid retention and prevention of diabetes related cardiovascular and renal complications, which are recognized problems with a number of existing glucose lowering drugs. ${ }^{10-12}$

SGLT 2 inhibitors are newer anti-hyperglycemic agents, which improve glycemic control independent of insulin secretion with a low risk of hypoglycemia. ${ }^{13}$ There is limited data on use of SGLT 2 inhibitors in Pakistan; this is a case series of local patients treated with SGLT 2 inhibitors. This study aimed to assess the efficacy of SGLT 2 inhibitors in terms of glycemic control, weight reduction and safety profile in cohort of Pakistani patients with T2D.

\section{METHODS}

This is a prospective analysis conducted at Medicell Institute of Diabetes, Endocrinology and Metabolism (MIDEM), Karachi Pakistan from January 2018 till July 2019. This study was approved by the ethical committee of MIDEM (IRB - 004/MHS/19).

Patients with T2D, who need escalation of treatment for failing to achieve $\mathrm{HbA1c}$ target on usual anti-diabetic drugs or a change of anti-diabetic medication required for purpose of cardiovascular and renal protective benefits of this class of drugs. All patients were counseled about the side effects and the need to report immediately if there were symptoms related to urinary, vulvo-vaginal or perineal infections.

\section{Inclusion Criteria:}

1. Patients with T2D, who needed escalation of treatment for failing to achieve $\mathrm{HbA} 1 \mathrm{c}$ target on standard anti-diabetic medication, including insulin $(\mathrm{HbA} 1 \mathrm{c} \geq 6.5)$.

2. Drug naive patients who meet ADA/EASD guideline specified criteria for using SGLT 2 inhibitors, i-e cardiovascular disease (CVD), chronic kidney disease (CKD) and Obesity

3. Patients on other anti-diabetic medications with existing CVD or mild CKD (eGFR $<90$ and $>30$ $\mathrm{mL} / \mathrm{min} / 1.73 \mathrm{~m} 2$ ) for beneficial effects of SGLT 2 inhibitors.

Exclusion Criteria: Patients with CKD, if eGFR $<30 \mathrm{~mL} / \mathrm{min} / 1.73 \mathrm{~m} .^{2}$ Patients with history of genital mycotic infections, recurrent urinary tract infections (UTIs), pyelonephritis, acute illness, T1D, pregnant or lactating women and history of diabetic ketoacidosis (DKA) in last 6 months.

Baseline weight, BMI, $\mathrm{HbA1c}$, fasting and random blood sugar, blood pressure, renal function and duration of diabetes were assessed.

The preexisting anti diabetic medication included Metformin, Sulphonylurea, DPP4 Inhibitors, Thiazolidinediones, GLP 1 Analogues or Insulin. The patients on insulin were either continued with the pre-existing dose of insulin or dose was reduced if there was risk of hypoglycemia. Likewise, dose of sulphonylurea was also reduced and was stopped in a few patients with hypoglycemia risk. Patients were advised to check blood glucose at-least twice per week and if they were unwell or had symptoms suggestive of hypoglycemia occurs. Hypoglycemia is defined as a blood sugar level below $70 \mathrm{mg} / \mathrm{dl}$ with or without symptoms. Diet and lifestyle were intensified.

The commercially available SGLT 2 inhibitors in Pakistan at the time of this study were Dapagliflozin 5- $10 \mathrm{mg}$ and Empagliflozin 10-25 $\mathrm{mg}$, and either of them were prescribed once daily in the morning, in addition to other anti-diabetic drugs. The duration of follow up was 3-6 months. Changes in weight, HbA1c, FBS, blood pressure, Cholesterol levels and Creatinine along with side effect profile were analyzed on follow up.

Statistical analysis: Frequency and percentages were presented for categorical variables that include gender, treatment assigned and adverse reactions reported during follow up visits. Mean and standard deviation was illustrated for age, weight, BP, T2D Duration, HbA1C and other numerical variables. Mean difference of $\mathrm{HbA1c}$, SBP, DBP, weight, FBS from baseline to followup (3-6 months) was analyzed by applying paired sample T-test through SPSS v.21, considering p-value $<0.001$ as statistically highly significant.

\section{RESULTS}

Our Study included a total of 140 patients; $53 \%$ were females and $47 \%$ were males. Baseline characteristics are given in Table-I. Mean Age was $55.6 \pm 10.3$ years. Mean weight at the time of starting SGLT $2 \mathrm{i}$ was $81.5 \pm 16.5 \mathrm{~kg}$; mean BMI was $31.9 \pm 7.7 \mathrm{~kg} / \mathrm{m}^{2}$. Mean systolic blood pressure at baseline was $144.1 \pm 19.5 \mathrm{mmHg}$ and diastolic blood pressure was $83.9 \pm 10.5 \mathrm{mmHg}$. Mean duration of T2D was $10.3 \pm 6.75$ years, 
Table-I: Baseline characteristics of study participants $(\mathrm{n}=140)$.

\begin{tabular}{lcc}
\hline Gender & \multicolumn{2}{c}{$75(53 \%)$} \\
Female & $65(47 \%)$ \\
Male & 55.6 & \pm 10.3 \\
Age (years), $\mathrm{n}=124$ & 57.03 & \pm 10.4 \\
Female (n=66) & 53.9 & \pm 10.1 \\
Male (n=55) & 81.5 & \pm 16.5 \\
Weight (Kg) & 31.9 & \pm 7.7 \\
Body Mass Index (Kg/m²) & 10.3 & \pm 6.75 \\
Duration of Diabetes Mellitus (years) & 144.1 & \pm 19.5 \\
Systolic Blood Pressure (mmHg) & 83.9 & \pm 10.5 \\
Diastolic Blood Pressure (mmHg) & 88.0 & \pm 10.9 \\
Heart Rate (Bpm) & 9.1 & \pm 1.6 \\
HbA1c (\%) & 190.3 & \pm 57.3 \\
Fasting Blood Sugar (mg/dL) & 255.7 & \pm 59.8 \\
Random Blood Sugar (mg/dL) & 169.5 & \pm 42.4 \\
Cholesterol (mg/dL) & 220.3 & \pm 161.7 \\
Triglyceride (mg/dL) & 38.2 & \pm 7.8 \\
High-Density Lipoproteins (mg/dL) & 99.7 & \pm 35.7 \\
Low-Density Lipoproteins (mg/dL) & 12.9 & \pm 1.58 \\
Hemoglobin (mg/dL) & 30.5 & \pm 18.2 \\
Alanine Aminotransferase (IU/L) & 0.93 & \pm 0.36 \\
Creatinine (mg/dL) & & \\
\hline
\end{tabular}

with a mean $\mathrm{HbA1C}$ at baseline of $9.1 \pm 1.6 \%$. Baseline creatinine of our study group was 0.9 $\mathrm{mg} / \mathrm{dl}$ and eGFR was $127.92 \mathrm{~mL} / \mathrm{min} / 1.73 \mathrm{~m}^{2}$. In our study group, $58(41.4 \%)$ patients were overweight/obese, 18 (12.8\%) had Ischemic Heart Disease (IHD) and 27 (19.2\%) patients had CKD. The patients were on different anti-diabetic medications: $87.1 \%$ on Metformin, $75.7 \%$ on DPP4 inhibitors, $31.4 \%$ on Sulphonylureas, $26.4 \%$ on Insulin, $7.9 \%$ on Pioglitazone and $6.5 \%$ were on GLP-1 agonist. Patients received two types of SGLT 2 inhibitors; $54.3 \%$ were given Dapagliflozin in the dose of $5-10 \mathrm{mg}$ per day, while $45.7 \%$ were given Empagliflozin in the dose of $10-25 \mathrm{mg}$ per day.

Follow up data was available for 90 patients at the time of analysis. Fifty Patients were lost to follow, approximately $40 \%$ of these patients, were still taking the drug but could not come and get the test done due to financial constraints or other issues. HbA1C improved considerably to $7.6 \pm 0.9$ $(\mathrm{P} \leq 0.001)$, at first follow-up between three to six months. Mean weight reduced to $78.5 \pm 16.1$ (P $\leq$ $0.003)$. There was significant reduction in systolic and diastolic blood pressures (Table-II) (Graph.1); with no deterioration of renal function (creatinine was $0.87 \mathrm{mg} / \mathrm{dl}$ ). The drug was discontinued in three patients; one had genital infection and 2 had excessive fatigue. Forty-two patients (30\%) reported increased frequency of urine; six patients $(4.3 \%)$ had fatigue, four patients $(2.9 \%)$ had UTI, followed by nausea and vomiting $(2.1 \%)$ and genital infection and burning hands and feet were reported in 1.4\% (Graph.2). No patient reported symptoms or documented hypoglycemia or euglycemic DKA.

\section{DISCUSSION}

With the increasing prevalence of $\mathrm{T} 2 \mathrm{D}$ and associated risk of CVD and CKD, SGLT 2 inhibitors represent a key therapeutic addition for clinicians in the management of patients with diabetes. Our study demonstrates that when SGLT 2 inhibitors were added at any stage of the disease in the real world scenario, in patients with uncontrolled T2D, there is a clinical and statistically significant improvement in glycemic control, weight loss and reduction in blood pressure in our patients, as has been demonstrated in the landmark studies with SGLT 2 inhibitors. ${ }^{14,15}$ This class of drug improves glycemic function independent of insulin secretion. In addition SGLT 2 inhibitors exert favorable effects on multiple risk factors including blood pressure, body weight and renal function; in addition they also provide an opportunity to reduce the risk of cardiovascular disease (CVD) in patients with T2D. ${ }^{14,15}$ Results of the EMPA-REG OUTCOME TRIAL, demonstrated a relative risk reduction of $38 \%, 35 \%$ and $32 \%$

Table-II: Effect of SGLT2 Inhibitors on HbA1c, Systolic Blood Pressure, Diastolic Blood Pressure, Weight, Fasting Blood Sugar from Baseline to Follow Up.

\begin{tabular}{lcccc}
\hline & Baseline $($ Mean \pm SD) & Follow up $($ Mean \pm SD) & Mean Difference & P-value \\
\hline HbA1c $(\mathrm{n}=72)$ & $8.9 \pm 1.6$ & $7.6 \pm 0.9$ & $1.3 \pm 1.3$ & $<0.001$ \\
SBP $(\mathrm{n}=90)$ & $146.8 \pm 19.8$ & $134.8 \pm 16.4$ & $12.1 \pm 19.4$ & $<0.001$ \\
DBP $(\mathrm{n}=90)$ & $85 \pm 11.0$ & $80.8 \pm 8.8$ & $4.1 \pm 10.6$ & $<0.001$ \\
Weight $(\mathrm{n}=89)$ & $80.8 \pm 18.1$ & $78.5 \pm 16.1$ & $2.3 \pm 6.9$ & 0.002 \\
Fasting Blood Sugar $(\mathrm{n}=51)$ & $202.2 \pm 59.4$ & $135.7 \pm 23.5$ & $66.4 \pm 54.7$ & $<0.001$ \\
\hline
\end{tabular}

Paired t-test was applied for statistical significance. 
Erum Sohail et al.

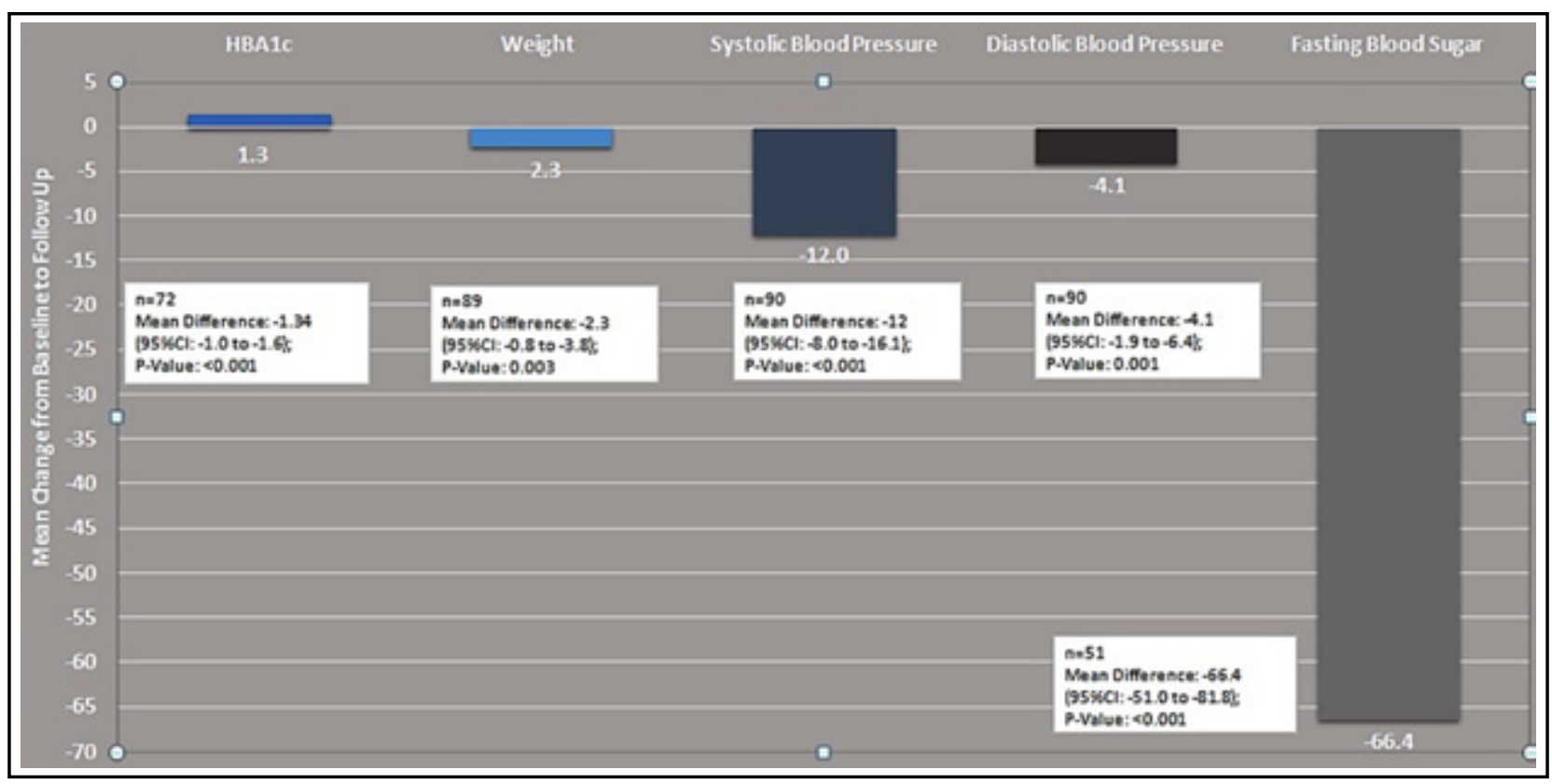

Graph.1: Effect of SGLT2 Inhibitors.

(Empagliflozin \& Dapagliflozin) on Systolic Blood Pressure, Diastolic Blood Pressure,

Weight, Fasting, Blood Sugar, Random Sugar from to Follow Up.

with respect to death from a cardiovascular event, hospitalization due to heart failure (HHF) and all-cause mortality respectively. ${ }^{16}$ Cardiovascular outcome trails (CVOTs) with other SGLT 2 inhibitors have also shown similar effects on cardiovascular complications along with a delay in renal function deterioration indicating an overall beneficial class effect. ${ }^{15,17,18} \mathrm{~A}$ recent study has demonstrated beneficial effects of Dapagliflozin in heart failure in patients without

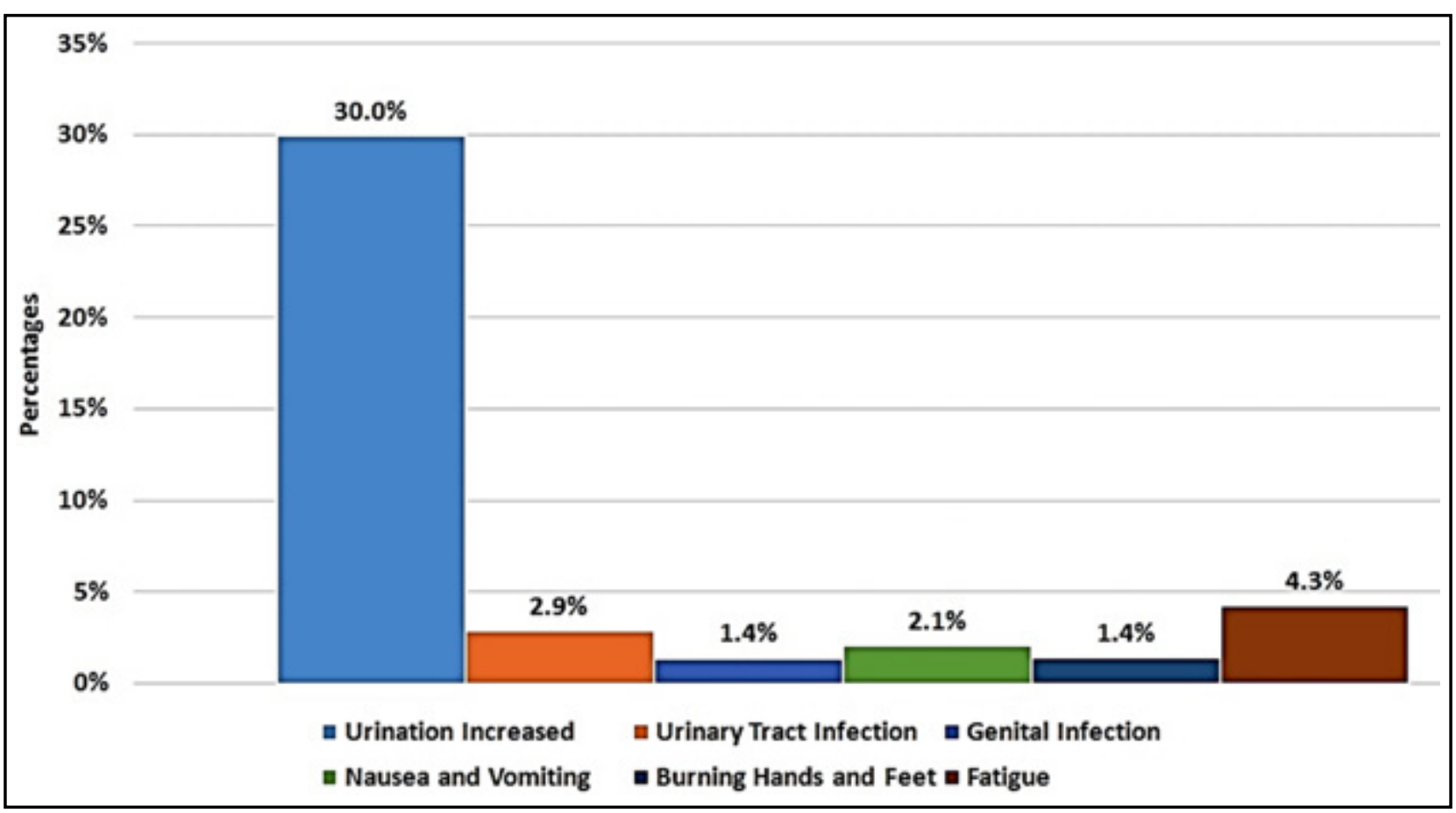

Graph.2: Patients Reported Adverse Events with SGLT2 Inhibitors (Empagliflozin \&Dapagliflozin) During Follow Up Visit ( $\mathrm{n}=140)$. 
diabetes, mandating a significant change in the guidelines for heart failure management. ${ }^{19}$

There is a paucity of data from South Asian countries specially Pakistan. This study aims to evaluate the effects and tolerability of this class of drugs in our population. In an Indian study, the mean $\mathrm{HbA} 1 \mathrm{c}$ reduction and weight reduction observed was $1.02 \pm 0.24 \%$ and $2.64 \pm 1.27 \mathrm{~kg}$ respectively. ${ }^{20}$ In another study from North India, $\mathrm{HbA1c}$ reduction observed was $1.8 \%$, while weight reduced by $-3.45 \mathrm{~kg} .{ }^{21}$ According to a recent metaanalysis of treatment with SGLT 2 inhibitors in Asian and non-Asian patients, reduction in $\mathrm{HbA} 1 \mathrm{c}$ levels was more in Asians than in non-Asians, with the difference of $0.05 \%$ between groups but was not significant $(\mathrm{P}>0.05) .{ }^{22}$ In a small study of Dapagliflozin in Turkish patients, $\mathrm{HbA1c}$ improved $1.6 \%$ with significant weight reduction and decrease in insulin dose. ${ }^{23} \mathrm{~A}$ recent publication on use of Dapagliflozin in Pakistan, reported mean $\mathrm{HbA} 1 \mathrm{c}$ and weight reduction of $-1.1 \%$ and $-1.98 \mathrm{~kg}$, respectively. ${ }^{24}$ Our study results are comparable to above studies with mean $\mathrm{HbA1c}$ reduction of $1.34 \%$ and mean weight reduction of $2.3 \mathrm{~kg}$.

SGLT 2i have additional advantage of blood pressure reduction. This effect is multifactorial mainly attributable to volume contraction by natriuretic and diuretic effects, weight loss, and better arterial compliance (elasticity index of large arteries). ${ }^{25}$ A meta-analysis which included 27 randomized controlled trials (n, 12 960) showed that SGLT 2 inhibitors significantly reduced both systolic (weighted mean difference, $-4.0 \mathrm{~mm} \mathrm{Hg}$ ) and diastolic blood pressure (weighted mean difference, $-1.6 \mathrm{~mm} \mathrm{Hg}$; [95\% CI, -1.9--1.3]. ${ }^{26}$ Patients in our study achieved similar magnitude of reduction in systolic and diastolic blood pressures.

SGLT 2 inhibitors are often associated with a risk of genital mycotic and lower UTI due to increased urinary excretion of glucose; these side effects being observed more often in women than in men. ${ }^{27}$ High risk of genital mycotic infections has been reported in a cohort of Indian patients with T2D on SGLT 2 inhibitors, one episode of genital mycotic infection occurred in $25.9 \%$ of patients and $12.2 \%$ had a second episode. ${ }^{28}$ The incidence of UTI and vulvo-vaginal candidiasis was very low in our study. Only two patients had genital infection and in one led to drug withdrawal, no case of perineal fasciitis was seen in this cohort. No patient reported symptoms of hypoglycemia or euglycemic DKA. This may be attributed to the fact, that we counseled our patients to increase water intake and the importance of maintaining good personal hygiene to avoid mycotic infections. Another Indian study, has reported similarly low incidence of adverse effects (AEs), including genitourinary AEs. ${ }^{26}$

Clinical studies have demonstrated that SGLT 2 inhibitors often induce an initial decrease in eGFR in patients with T2D; subsequently eGFR remains stable over time and returns toward baseline during continuous SGLT 2 inhibition. ${ }^{14,15}$ This initial increase in eGFR was noted in $23(25 \%)$ patients in our cohort.

Limitations of the study: Limitation of our study is its small sample size and inability to report on the follow up of all patients prescribed SGLT 2 inhibitors in this cohort. We did not compare the effect of SGLT 2 inhibitors with other anti-diabetic drugs in a controlled manner. Since this was a short study, we did not assess the effect of SGLT 2 inhibitors on long term cardiovascular and renal outcomes.

\section{CONCLUSION}

Mean reduction of $\mathrm{HbA1c}(-1.34 \%)$ showed that Dapagliflozin and Empagliflozin offer a significant additional drug for improving glycemic control with the additional advantage of hypoglycemia safety and cardiovascular and renal benefit without any significant side effects in our population.

Acknowledgement: The authors wish to acknowledge the support of Mahwish Raza, Medical Affairs department of Getz Pharma for providing technical support in statistical analysis and Dr. Bharta Rani for her contribution in data assimilation and keeping records of patients.

Conflict of Interest: None.

\section{REFERENCES}

1. Saeedi P, Petersohn I, Salpea P, Malanda B, Karuranga S, Unwin N, et al. Global and regional diabetes prevalence estimates for 2019 and projections for 2030 and 2045: Results from the International Diabetes Federation Diabetes Atlas, 9th edition. Diabetes Res ClinPract. 2019;157:107843. doi: 10.1016/j.diabres.2019.107843

2. Yeung RO, Zhang Y, Luk A, Yang W, Sobrepena L, Yoon KH, et al. Metabolic profiles and treatment gaps in young-onset type 2 diabetes in Asia (the JADE programme): a cross-sectional study of a prospective cohort. Lancet Diabetes Endocrinol. 2014;2(12):935-943. doi :10.1016/S2213-8587(14)70137-8

3. Moller JB, Pedersen M, Tanaka H, Ohsugi M, Overgaard RV, Lynge J, et al. Body composition is the main determinant for the difference in type 2 diabetes pathophysiology between Japanese and Caucasians. Diabetes Care. 2014;37(3):796-804. doi: $10.2337 /$ dc13-0598 
4. Dickinson S, Colagiuri S, Faramus E, Petocz P, Brand-Miller JC. Postprandial hyperglycemia and insulin sensitivity differ among lean young adults of different ethnicities. J Nutr. 2002;132(9):2574-2579. doi: 10.1093/jn/132.9.2574

5. Liew CF, Seah ES, Yeo KP, Lee KO, Wise SD. Lean, nondiabetic Asian Indians have decreased insulin sensitivity and insulin clearance, and raised leptincompared to Caucasians and Chinese subjects. Int J Obes Relat Metab Disord. 2003;27(7):784-789. doi: 10.1038 /sj.ijo.0802307

6. Huxley R, James WP, Barzi F, Patel JV, Lear SA, Suriyawongpaisal $\mathrm{P}$, et al. Ethnic comparisons of the crosssectional relationships between measures of body size with diabetes and hypertension. Obes Rev. 2008;9(Suppl1):53-61. doi: 10.1111/j.1467-789X.2007.00439.x

7. Sheu WH, Rosman A, Mithal A, Chung N, Lim YT, Deerochanawong $\mathrm{C}$, et al. Addressing the burden of type 2 diabetes and cardiovascular disease through the management of postprandial hyperglycaemia: an Asian-Pacific perspective and expert recommendations. Diabetes Res ClinPract. 2011;92(3):312-321. doi: 10.1016/j. diabres.2011.04.019

8. Basit A, Fawwad A, Qureshi H, Shera AJBo. Correction: Prevalence of diabetes, pre-diabetes and associated risk factors: second National Diabetes Survey of Pakistan (NDSP), 2016-2017. BMJ Open. 2019;8(11):e020961corr020961. doi: 10.1136/ bmjopen-2017-020961corr1

9. Aamir AH, Ul-Haq Z, Mahar SA, Qureshi FM, Ahmad I, Jawa A, et al. Diabetes Prevalence Survey of Pakistan (DPS-PAK): prevalence of type 2 diabetes mellitus and prediabetes using HbA1c: a population-based survey from Pakistan. BMJ Open. 2019;9(2):e025300. doi: 10.1136/ bmjopen-2018-025300

10. Brunton SA. Hypoglycemic potential of current and emerging pharmacotherapies in type 2 diabetes mellitus. Postgrad Med. 2012;124(4):74-83. doi: 10.3810/ pgm.2012.07.2570

11. Morgan CL, Jenkins-Jones S, Evans M, Barnett AH, Poole CD, Currie CJ. Weight change in people with type 2 diabetes: secular trends and the impact of alternative antihyperglycaemic drugs. Diabetes Obes Metab. 2012;14(5):424-432. doi: 10.1111/j.14631326.2011.01552.x

12. Mudaliar S, Chang AR, Aroda VR, Chao E, Burke $\mathrm{P}$, Baxi S, et al. Effects of intensive insulin therapy alone and with added pioglitazone on renal salt/ water balance and fluid compartment shifts in type 2 diabetes. Diabetes Obes Metab. 2010;12(2):133-138. doi: 10.1111/j.1463-1326.2009.01126.x

13. Meng W, Ellsworth BA, Nirschl AA, McCann PJ, Patel M, Girotra RN, et al. Discovery of dapagliflozin: a potent, selective renal sodium-dependent glucose cotransporter 2 (SGLT 2) inhibitor for the treatment of type 2 diabetes. J Med Chem. 2008;51(5):1145-1149. doi: $10.1021 /$ jm701272q

14. Muskiet $\mathrm{MH}$, van Raalte $\mathrm{DH}$, van Bommel EJ, Smits MM, Tonneijck L. Understanding EMPA-REG OUTCOME. Lancet Diabetes Endocrinol. 2015;3(12):928-929. doi: 10.1016/S2213-8587(15)00424-6

15. Mahaffey KW, Neal B, Perkovic V, de Zeeuw D, Fulcher G, Erondu N, et al. Canagliflozin for Primary and Secondary Prevention of Cardiovascular Events: Results From the CANVAS Program (Canagliflozin Cardiovascular Assessment Study). Circulation. 2018;137(4):323-334. doi: 10.1161/ CIRCULATIONAHA.117.032038

16. Zinman B, Wanner C, Lachin JM, Fitchett D, Bluhmki E, Hantel S, et al. Empagliflozin, Cardiovascular Outcomes, and Mortality in Type 2 Diabetes. N Engl J Med. 2015;373(22):21172128. doi: 10.1056/NEJMoa1504720

17. Wiviott SD, Raz I, Bonaca MP, Mosenzon O, Kato ET, Cahn A, et al. Dapagliflozin and Cardiovascular Outcomes in Type 2 Diabetes. N Engl J Med. 2019;380(4):347-357. doi: 10.1056/NEJMoa1812389
18. Mahaffey KW, Jardine MJ, Bompoint S, Cannon CP, Neal B, Heerspink HJL, et al. Canagliflozin and Cardiovascular and Renal Outcomes in Type 2 Diabetes Mellitus and Chronic Kidney Disease in Primary and Secondary Cardiovascular Prevention Groups. Circulation. 2019;140(9):739-750. doi: 10.1161/CIRCULATIONAHA.119.042007

19. AstraZeneca. Study to evaluate the effect of dapagliflozin on the incidence of worsening heart failure or cardiovascular death in patients with chronic heart failure (Dapa-HF).

20. Prasanna Kumar KM, Mohan V, Sethi B, Gandhi P, Bantwal G, Xie J, et al. Efficacy and safety of canagliflozin in patients with type 2 diabetes mellitus from India. Indian J Endocrinol Metab. 2016;20(3):372-380. doi:10.4103/2230-8210.179996

21. Ghosh A, Gupta R, Singh P, Dutta A, Misra A. Sodium-glucose cotransporter-2 inhibitors in patients with type 2 diabetes in North India: A 12-month prospective study in real-world setting. Int J Clin Pract. 2018;72(9):e13237. doi: 10.1111/ ijcp.13237

22. Cai X, Gao X, Yang W, Chen Y, Zhang S, Zhou L, et al. No disparity of the efficacy and all-cause mortality between Asian and non-Asian type 2 diabetes patients with sodiumglucose cotransporter 2 inhibitors treatment: A meta-analysis. J Diabetes Investig. 2018;9(4):850-861. doi: 10.1111/jdi.12760

23. Sertbas M, Sertbas Y, Okuroglu N, Akyildiz AB, Sancak S, Ozdemir A. Efficacy and safety of dapagliflozin on diabetic patients receiving high-doses of insulin. Pak J Med Sci. 2019;35(2):399-403. doi:10.12669/pims.35.2.21

24. Kamin M, Ishtiaq O, Raashid K, Wahab MU, Khan SA, Raja U. The outcomes of dapagliflozin use in real-life clinical settings in endocrinology clinics of Islamabad, Pakistan. Cureus. 2020 Jun;12(6).

25. DeFronzo RA, Norton L, Abdul-Ghani M. Renal, metabolic and cardiovascular considerations of SGLT 2 inhibition. Nat Rev Nephrol. 2017;13(1):11-26. doi: 10.1038/nrneph.2016.170

26. Baker WL, Smyth LR, Riche DM, Bourret EM, Chamberlin KW, White WB. Effects of sodium-glucose co-transporter2 inhibitors on blood pressure: a systematic review andmetaanalysis. J Am Soc Hypertens. 2014;8(4):262-275.e269. doi: 10.1016/j.jash.2014.01.007

27. Viswanathan V, Singh KP. Use of Dapagliflozin in the Management of Type 2 Diabetes Mellitus: A Real-World Evidence Study in Indian Patients (FOREFRONT). Diabetes Technol Ther. 2019;21(8):415-422. doi: 10.1089/dia.2019.0052

28. Aggarwal A, Wadhwa R, Kapoor D, Khanna R. High Prevalence of Genital Mycotic Infections with Sodium-glucose Co-transporter 2 Inhibitors among Indian Patients with Type 2 Diabetes. Indian J Endocrinol Metab. 2019;23(1):9-13. doi: 10.4103/ijem.IJEM_244_18

\section{Author`s Contribution:}

ES: Contributed to conception and design of the study, Data acquisition, analysis and interpretation, Drafting the article and Final approval of the version to be published and responsible and accountable for this study.

TA: Accuracy and Integrity of the work, Contribution to conception and design of the study, Patient management, Critical analysis of the article and Final approval of the version to be published

SG: Contributed to conception and design of the study, Data acquisition and collection and Revision of article.

WA: Conception and design of study and Data acquisition and collection. 